\title{
Potencial antifúngico de extratos de plantas e de basidiomicetos nativos sobre Colletotrichum acutatum, Alternaria solani e Sclerotium rolfsii
}

\author{
Ricardo José Domingues ${ }^{1}$, Maria Cláudia Marx Young ${ }^{2}$, Jesus Guerino Töfoli ${ }^{1}$, Dácio Roberto Matheus ${ }^{3}$
}

\begin{abstract}
${ }^{1}$ APTA / Instituto Biológico, CPDSV, Av. Cons. Rodrigues Alves, 1252. CEP.: 04014-002, São Paulo, SP; ${ }^{2}$ Instituto de Botânica, Seção de Fisiologia e Bioquímica de Plantas, São Paulo, SP ${ }^{3}$ Instituto de Botânica, Seção de Micologia e Liquenologia, São Paulo, SP.

Autor para correspondência: Ricardo José Domingues (domingues@biologico.sp.gov.br)

Data de chegada: 01/07/2009. Aceito para publicação em: 03/06/2011.
\end{abstract}

\section{RESUMO}

Domingues, R.J.; Young, M.C. M.; Töfoli, J.G.; Matheus, D.R. Avaliação do potencial antifúngico de extratos de plantas e de basidiomicetos nativos sobre Colletotrichum acutatum, Alternaria solani e Sclerotium rolfsii. Summa Phytopathologica, v.37, n.3, p.149-151, 2011.

O emprego de fungicidas na agricultura, principalmente quando utilizados de forma inadequada, tem provocado danos tanto ao homem como ao ambiente. O presente trabalho teve por objetivo o estudo in vitro da eficácia de extratos de três plantas e de dois basidiomicetos nativos do Brasil no controle dos fungos Alternaria solani e Colletotrichum acutatum, causadores de graves prejuízos às culturas de tomate e morango, respectivamente, além de Sclerotium rolfsii, considerado como patógeno polífago. No trabalho foram avaliados: a) a inibição de crescimento micelial dos três fitopatógenos, b) inibição da germinação de conídios de A. solani e C. acutatum e c) inibição da germinação de escleródios de $S$. rolfsii. Os melhores resultados foram obtidos com o extrato de Oudemansiella canarii, que proporcionou os menores valores de crescimento micelial dos três patógenos, além inibir totalmente a germinação de conídios de A. solani e C. acutatum e de escleródios de S. rolfsii. O extrato de Irpex lacteus inibiu parcialmente o crescimento micelial dos patógenos estudados e o extrato de Avicennia schaueriana promoveu apenas $16 \%$ de inibição do crescimento micelial de $S$. rolfsii. Nenhum efeito sobre os patógenos foi verificado com os extratos de Senna spectabilis e Senna multijuga nas condições em que foram realizados os experimentos.

Palavras-chave adicionais: Avicennia schaueriana, Senna spectabilis, Senna multijuga, Irpex lacteus, Oudemansiella canarii, produtos naturais.

\section{ABSTRACT}

Domingues, R.J.; Young, M.C.M.; Töfoli, J.G.; Matheus, D.R. Antifungal potential of extracts of native plants and basidiomycetes on Colletotrichum acutatum, Alternaria solani and Sclerotium rolfsii. Summa Phytopathologica, v.37, n.3, p.149-151, 2011.

The use of fungicides in agriculture, especially when inadequate, has caused damages to both the environment and humans. The present study aimed to investigate in vitro the efficacy of extracts of three plants and two basidiomycetes of the Brazilian flora in controlling Alternaria solani and Colletotrichum acutatum, which causes serious damages to tomato and strawberry crops, respectively, and Sclerotium rolfsii, considered as non-specific pathogen. This work evaluated: a) mycelial growth inhibition for the three phytopathogens, b) conidial germination inhibition (A. solani and C. acutatum) and c) sclerotial germination inhibition for $S$. rolfsii. The best results were obtained with Oudemansiella canarii extract, which provided the lowest mycelial growth values for the three pathogens, besides totally inhibiting A. solani and $C$. acutatum conidial germination and $S$. rolfsii sclerotial germination. I. lacteus extract partially inhibited the mycelial growth of the pathogens and Avicennia schaueriana promoted only $16 \%$ inhibition in $S$. rolfsii mycelial growth. Senna spectabilis and Senna multijuga extracts had no effect on the pathogens under the conditions of the present experiments.

Keywords: Avicennia schaueriana, Senna spectabilis, Senna multijuga, Irpex lacteus, Oudemansiella canarii, natural products.

A flora brasileira é considerada a mais rica do mundo com cerca de 56.000 espécies de plantas (5) e entre 12,5 e 13,5 mil espécies de fungos (8). No entanto, com exceção de espécies de importância medicinal, muito pouco conhecemos a respeito da composição química de 99,6\% das espécies de plantas nacionais.

Diversos metabólitos secundários produzidos pelas plantas possuem funções de defesa contra herbívoros, pragas e patógenos (3). Moléculas complexas como terpenóides, alcalóides e compostos fenólicos são sintetizados pelo metabolismo secundário das plantas e são de grande importância nas relações ecológicas planta/planta, planta/ animal e, inclusive, planta/microrganismo fitopatogênico. Tais substâncias são consideradas como produtos naturais e representam uma fonte alternativa quase inesgotável de novas moléculas com potencial para serem utilizados no controle químico de doenças.

Alternaria solani (ELL. \& Martin) Jones \& Grout, Colletotrichum acutatum Simmonds e Sclerotium rolfsii Sacc. são fungos fitopatogênicos capazes de provocar danos severos a espécies olerícolas de grande importância econômica. A. solani, agente causal da doença conhecida como "pinta preta" está entre os principais patógenos de folhas, hastes e frutos do tomateiro (1). A "flor preta", causada por $C$. acutatum, é considerada o principal problema fitossanitário da cultura do morangueiro, podendo infectar flores, frutos, pedúnculos, folhas, meristemas apicais e parte superior do rizoma (10). S. rolfsii é um organismo que faz parte da microbiota do 
solo. É considerado patógeno causador de podridão de raiz e colo, podendo atacar diversas espécies de plantas em todos os seus estádios de desenvolvimento (1).

O objetivo do presente trabalho foi avaliar o potencial dos extratos de três espécies de plantas e duas espécies de basidiomicetos nativos na inibição in vitro do crescimento micelial e das estruturas reprodutivas e/ou de sobrevivência de A. solani, C. acutatum e $S$. rolfsii.

As culturas dos fungos Oudemansiella canarii (CCB179) e Irpex lacteus (CCB 196) foram fornecidas pela Seção de Micologia e Liquenologia do Instituto de Botânica (Secretaria do Meio Ambiente$\mathrm{SP})$. Os extratos das plantas fanerógamas nativas Senna spectabilis, Senna multijuga e Avicennia schaueriana foram fornecidos pela extratoteca da Seção de Fisiologia e Bioquímica de Plantas do mesmo Instituto e os três patógenos foram isolados de amostras apresentando sintomas coletadas em plantios comerciais de Piedade, SP e mantidos na micoteca do Centro de Pesquisa e Desenvolvimento de Sanidade Vegetal do Instituto Biológico.

Os extratos de $O$. canarii e I. lacteus foram elaborados utilizandose metodologia modificada a partir da empregada por Rosa et al. (9) e foram armazenados a $-10{ }^{\circ} \mathrm{C}$ até a realização dos ensaios. Os extratos etanólicos de flores de $S$. spectabilis e folhas de $S$. multijuga, foram obtidos a partir da secagem e moagem do material e, em seguida, da extração utilizando-se um aparelho modelo ASE 300 - Accelerated Solvent Extractor. Os extratos etanólicos obtidos foram concentrados sob pressão reduzida a $40{ }^{\circ} \mathrm{C}$ em evaporador rotatório. Com o extrato parcialmente concentrado, a amostra foi distribuída em frascos de 5 $\mathrm{mL}$ e seca em banho-maria a $60{ }^{\circ} \mathrm{C}$ por 72 horas.

$\mathrm{O}$ extrato clorofórmico de A. schaueriana foi obtido macerando o pó seco das folhas em álcool etílico em temperatura ambiente. Após filtração, a solução etanólica foi concentrada em evaporador rotatório, levada ao banho-maria a $60{ }^{\circ} \mathrm{C}$ para obtenção do resíduo etanólico. Em seguida, o resíduo foi redissolvido com metanol+água destilada e particionado com hexano. A fração hexânica foi filtrada e concentrada em evaporador rotatório. À fração hidrometanólica foi adicionada água destilada e depois particionada com clorofórmio, originando o resíduo clorofórmico após a eliminação do solvente.

A avaliação do efeito dos extratos sobre o crescimento micelial dos patógenos foi feita através da diluição em meio de cultura BDA. Os extratos vegetais e fúngicos foram dissolvidos previamente em acetona e dimetil sulfóxido, respectivamente. A seguir, foram adicionados ao BDA nas concentrações de 0 e $1000 \mathrm{mg} \cdot \mathrm{mL}^{-1}$ e vertidos em placas de Petri $(5 \mathrm{~cm} \varnothing)$. Discos de BDA com micélio dos patógenos foram transferidos para as placas e incubados em BOD a $25{ }^{\circ} \mathrm{C}$ em ausência de luz. A avaliação foi realizada quando as parcelas testemunhas foram completamente tomadas pelos fungos, medindo-se o crescimento radial dos fungos em dois sentidos.

Para a avaliação do efeito dos extratos sobre a inibição da germinação de conídios de $C$. acutatum e $A$. solani, foi utilizado o método do celofane descrito por Nelly (7). Os extratos vegetais e fúngicos foram dissolvidos previamente em acetona e dimetil sulfóxido, respectivamente. Discos de papel celofane foram colocados em placas de Petri sobre discos de papel de filtro embebidos com a solução de cada extrato nas concentrações 0 e $1000 \mathrm{mg} \cdot \mathrm{mL}^{-1}$. A seguir, uma gota de suspensão de conídios de A. solani, e C. acutatum, na concentração de $10^{4}$ conídios. $\mathrm{mL}^{-1}$ foi depositada sobre cada disco de celofane. As placas foram mantidas em BOD sob fotoperíodo de $12 \mathrm{~h}$ e $25{ }^{\circ} \mathrm{C}$. A avaliação de germinação dos conídios foi feita transferindo-se os discos de celofane para uma lâmina de vidro, com o auxílio de uma pinça, sobre a qual foram colocadas uma gota de água e uma lamínula. A observação foi feita em microscópio óptico após 16 h de incubação contando-se de 100 conídios e considerando-se como germinados, os que apresentassem indício de formação do tubo germinativo. $\mathrm{O}$ delineamento experimental foi inteiramente casualizado com três repetições, sendo cada parcela constituída por uma placa de Petri com 10 discos de celofane.

O efeito dos extratos sobre a germinação de escleródios de $S$. rolfsii foi estudado depositando-se dez escleródios em placas de Petri contendo meio de cultura BDA e cada um dos extratos, preparadas de forma semelhante ao experimento de inibição do crescimento micelial já descrito e incubadas por $72 \mathrm{~h}$ a $25^{\circ} \mathrm{C}$ e fotoperíodo de $12 \mathrm{~h}$. O delineamento experimental foi inteiramente casualizado com cada parcela sendo composta por 10 placas por extrato contendo 10 escleródios cada. A avaliação foi feita contando-se os escleródios germinados e calculando-se a porcentagem de germinação.

Em todos os experimentos, tratamentos contendo dimetil sulfóxido, acetona e extrato de meio de cultura MEC (extrato de malte a $2 \%$, peptona a $0,1 \%$ e glicose a $1,5 \%$ ) foram utilizados como controle negativo.

Considerando-se os valores de inibição do crescimento micelial e germinação de escleródios de $S$. rolfsii expressos na Tabela 1, pode-se concluir que os extratos dos dois basidiomicetos foram mais eficientes do que os extratos vegetais. O. canarii foi o que proporcionou os melhores resultados atingindo a média de $84 \%$ de inibição do crescimento micelial, além de não permitir a germinação de escleródios. A porcentagem de inibição pelo extrato de I. lacteus foi inferior ao de O. canarii, mas foi mais eficiente que os demais extratos. Dentre os

Tabela 1 - Crescimento micelial (diâmetro em $\mathrm{cm}$ ), porcentagem de inibição do crescimento micelial e porcentagem de germinação de escleródios de Sclerotium rolfsii e de conídios de Alternaria solani e Colletotrichum acutatum quando submetidos à ação de extratos na concentração de 1000 g. $\mathrm{mL}^{-1}$, em relação à testemunha.

\begin{tabular}{|c|c|c|c|c|c|c|c|c|c|}
\hline \multirow[b]{2}{*}{ Origem dos extratos } & \multicolumn{3}{|c|}{ Sclerotium rolfsii } & \multicolumn{3}{|c|}{ Alternaria solani } & \multicolumn{3}{|c|}{ Colletotrichum acutatum } \\
\hline & $\begin{array}{l}\text { Diâm. } \\
\text { (cm) }\end{array}$ & $\begin{array}{c}\text { Inibição } \\
(\%)\end{array}$ & $\begin{array}{c}\text { Germ. de } \\
\text { escleródios }(\%)\end{array}$ & $\begin{array}{c}\text { Diâm. } \\
\text { (cm) }\end{array}$ & $\begin{array}{c}\text { Inibição } \\
(\%)\end{array}$ & $\begin{array}{c}\text { Germ. de } \\
\text { escleródios }(\%)\end{array}$ & $\begin{array}{l}\text { Diâm. } \\
\text { (cm) }\end{array}$ & $\begin{array}{c}\text { Inibição } \\
(\%)\end{array}$ & $\begin{array}{c}\text { Germ. de } \\
\text { escleródios }(\%)\end{array}$ \\
\hline Oudemansiella canarii & $0,9 \quad \mathrm{~d}$ & 84,0 & $0,0 \quad \mathrm{c}$ & 1,5 & c 69,3 & 0,0 & 0,8 & 83,3 & 0,0 \\
\hline Avicennia schaueriana & $4,2 \mathrm{~b}$ & 16,0 & $100,0 \mathrm{a}$ & $5,0 \mathrm{a}$ & 0,0 & 100,0 & $5,0 \mathrm{a}$ & 0,0 & 86,1 a \\
\hline Testemunha & $5,0 \mathrm{a}$ & “ & $100,0 \mathrm{a}$ & $5,0 \mathrm{a}$ & “ & 100,0 & $5,0 \mathrm{a}$ & “ & 30,4 \\
\hline $\mathrm{CV}(\%)$ & 2,7 & & 5,0 & 0,8 & & & 1,7 & & 7,6 \\
\hline
\end{tabular}

Médias seguidas de mesma letra não diferem estatisticamente entre si pelo teste de Tukey a $5 \%$ de probabilidade. 
extratos de plantas o que mais se destacou foi o de A. schaueriana com $16 \%$ de inibição do crescimento micelial, sendo semelhante aos de $S$. spectabilis e $S$. muiltijuga quanto à germinação de escleródios.

Para A. solani os resultados foram semelhantes aos obtidos com $S$. rolfsii, com redução do crescimento micelial pelo extrato de $O$. canarii, sendo estatisticamente mais eficiente que os demais. O extrato de $I$. lacteus proporcionou nível intermediário de inibição, com crescimento menor em relação aos extratos vegetais, os quais não diferiram da testemunha. Apenas o extrato de $O$. canarii não permitiu a germinação de conídios de A. solani. Os outros extratos não apresentaram nenhum grau de inibição.

O extrato de $O$. canarii foi o que proporcionou maior porcentagem de inibição do crescimento micelial de C. acutatum. A inibição do crescimento pelo extrato de I. lacteus foi estatisticamente superior aos extratos vegetais atingindo $50,0 \%$. A. schaueriana, S. spectabilis e $S$. multijuga não apresentaram ação sobre os patógenos. $\mathrm{O}$ extrato $O$. canarii foi o único a não permitir a germinação de conídios de $C$. acutatum.

A ação antimicrobiana de metabólitos de Oudemansiella foi descrita pela primeira vez por Anke et al. (2), a partir de estudos com $O$. mucida. Os autores relataram que quanto à estrutura molecular, a substância ativa que foi isolada (oudemansina), mostrou-se semelhante a estrobilurina $\mathrm{A}\left(\mathrm{C}_{16} \mathrm{H}_{18} \mathrm{O}_{3}\right)$ a qual, depois de muitos anos de pesquisa originou o grupo de fungicidas denominado estrobilurinas. Tais fungicidas apresentam como mecanismo de ação característico, a interferência na respiração mitocondrial, bloqueando assim, a transferência de elétrons pelo complexo citocromo bc1, através da inibição da óxido-redutase de ubihidroquinona-citocromo c. $O$. canarii provavelmente também produz oudemansina, o que explicaria o excelente desempenho verificado.

A ação fungicida de I. lacteus já foi relatada por outros autores. Koitabashi \& Tsushima (6) incubando folhas de trigo inoculadas com Blumeria graminis f.sp. tritici, agente causal do oídio do trigo, na presença de I. lacteus sem que houvesse contato entre eles, verificaram alta inibição do patógeno por dois tipos de compostos voláteis: 5pentil-2-furaldeído e 5-(4-pentenil)-2-furaldeído. Também verificaram o efeito supressivo destes compostos sobre Penicillium sp. e Aspergillus sp.

A indução da germinação de conídios de $C$. acutatum observada com os extratos vegetais e de I. lacteus, já foi verificada por Bonaldo $\&$ Pascholati (4) com Colletotrichum sublineolum e C. lagenarium, quando utilizou frações purificadas de Saccharomyces cerevisiae. Este efeito pode ser explicado pela presença nos extratos de substâncias estimuladoras, de nutrientes ou pela inativação da micosporina-alanina, um auto inibidor presente na mucilagem que envolve os conídios.
Tais resultados reforçam a importância dos fungos basidiomicetos e de plantas fanerógamas da flora nacional, como fontes de substâncias com elevada ação antifúngica sobre fitopatógenos, justificando a necessidade urgente da preservação dos ecossistemas em que vivem enquanto são melhor estudados.

\section{REFERÊNCIAS BIBLIOGRÁFICAS}

1. Agrios, G. N. Plant pathology. 5 ed. San Diego: Academic Press. 2005. 922 p.

2. Anke, T.; Hecht, H.J.; Schramm, G.; Steglich, W. Antibiotics from basidiomycetes. IX Oudemansin, an aintifungal antibiotic from Oudemansiella mucida (Schader ex Fr.) Hoenel (Agaricales). The Journal of Antibiotics, Tokio,v.32, n.11, p.1112-1117, 1979.

3. Bennett, R.N.; Wallsgrove, R.M. Secondary metabolites in plant defence mechanisms. New Phytoligist, Philadelphia, v.4, n.127, p.617-633. 1994.

4. Bonaldo, S.M.; Pascholati, S.F. Efeito de frações purificadas de Saccharomyces cerevisiae na germinação de conídios e formação de apressórios por Colletotrichum sublineolum e Colletotrichum lagenarium. Summa Phytopathologica, Botucatu, v.33, n.3, p.233-238, 2007.

5. Brasil. Ministério do Meio Ambiente. Instituto Brasileiro do Meio Ambiente e dos Recursos Naturais Renovávies. Estudos da representatividade ecológica nos biomas brasileiros. Brasília, 2007. Disponível em: <http://www.ibama.gov.br/ecossistemas/ estudos.htm >. Acesso em: 7 dez. 2007.

6. Koitabashi, M.; Tsushima, S. Studies of biocontrol of air-borne plant disease by a filamentous fungus producing antifungal volatiles. Japan Agricultural Research Quarterly: Tokyo, v.41, n.4, p.261-265, 2007.

7. Nelly, D. Laboratory and greenhouse procedures methods for evaluation fungicides, nematicides and bactericides. Minessota: American Phytophathological Society, 1978. 140 p.

8. Peixoto, A.L. ; Morim, M.P. Coleções botânicas: documentação da biodiversidade brasileira. Ciência e Cultura, São Paulo, v.55, n.3, p.21-24, 2007. Disponível em: <http://cienciaecultura.bvs.br/

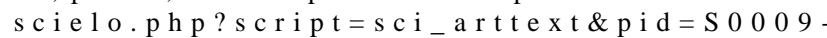
$67252003000300016 \& \operatorname{lng}=$ en $\& n r m=i s o>$. Acesso em 15 out. 2008.

9. Rosa, L.H.; Machado, K.M.G.; Jacob, C.C.; Capelari, M.; Rosa, C.A.; Zani, C.L. Screening of Brazilian Basisiomycetes for Antimicrobial Activity. Memórias do Instituto Oswaldo Cruz, Rio de Janeiro, v.98, n.7, p.967-974, 2003.

10. Tanaka, M. A. S.; Betti, J. A.; Kimati, H. Doenças do morangueiro-Fragaria $x$ ananassa Duch. In: Kimati, H.; Amorin, L.; Rezende, J. A.; Bergamin Filho, A.; Camargo, L. E. A. (Eds.). Manual de fitopatologia: doenças das plantas cultivadas. 4. ed. São Paulo: Agronômica Ceres, 2005. v.2, p.489-499. 